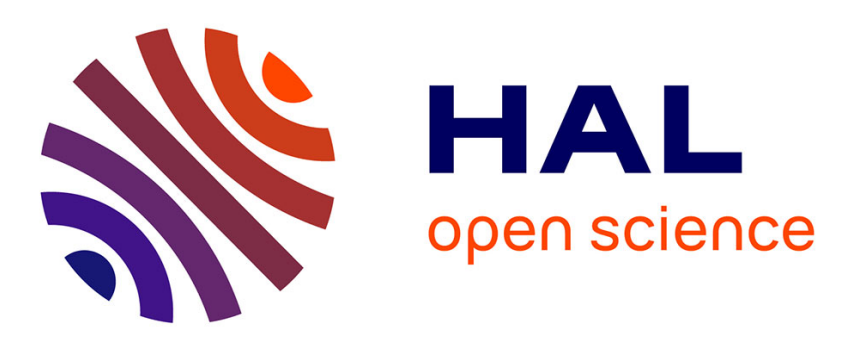

\title{
Value of gene polymorphisms as markers of 5-FU therapy response in stage III colon carcinoma: a pilot study
}

Arantza Fariña-Sarasqueta, Gesina Lijnschoten, Harm J. T. Rutten, Adriaan J. C. van den Brule

\section{To cite this version:}

Arantza Fariña-Sarasqueta, Gesina Lijnschoten, Harm J. T. Rutten, Adriaan J. C. van den Brule. Value of gene polymorphisms as markers of 5-FU therapy response in stage III colon carcinoma: a pilot study. Cancer Chemotherapy and Pharmacology, 2010, 66 (6), pp.1167-1171. 10.1007/s00280010-1403-0 . hal-00612022

\section{HAL Id: hal-00612022 https://hal.science/hal-00612022}

Submitted on 28 Jul 2011

HAL is a multi-disciplinary open access archive for the deposit and dissemination of scientific research documents, whether they are published or not. The documents may come from teaching and research institutions in France or abroad, or from public or private research centers.
L'archive ouverte pluridisciplinaire HAL, est destinée au dépôt et à la diffusion de documents scientifiques de niveau recherche, publiés ou non, émanant des établissements d'enseignement et de recherche français ou étrangers, des laboratoires publics ou privés. 
4 Value of gene polymorphisms as markers of 5-FU therapy response in stage III colon carcinoma: a 5 pilot study

8 Arantza Fariña-Sarasqueta ${ }^{1,2}$, Gesina van Lijnschoten ${ }^{1}$, Harm, J.T. Rutten ${ }^{3}$, Adriaan J.C. van den Brule ${ }^{1}$

$9{ }^{1}$ Department of Molecular Diagnostics, PAMM laboratory of pathology, Michelangelolaan 2, 5029 EJ

10 Eindhoven, the Netherlands

$11{ }^{2}$ Department of Applied Sciences, Fontys University of Applied Science, Rachelsmolen 1, 5612 MA

12 Eindhoven, the Netherlands

$13{ }^{3}$ Department of surgery, Catharina hospital Eindhoven, Michelangelolaan 2, 5029 EJ, Eindhoven, the

14 Netherlands

15

16 Disclosures: None

21 Corresponding author

22 A.J.C. van den Brule, $\mathrm{PhD}$

23 Department of Molecular Diagnostics

24 PAMM laboratory of pathology

25 Michelangelolaan 2

265029 EJ Eindhoven

27 The Netherlands

28 Phone: +31 (0)40-239 6100

29 Fax: +31 (0)40- 2396109

30 Email: a.van.den.brule@pamm.nl 


\section{Abstract}

2 Purpose: The role of pharmacogenetics in chemotherapy response in colon carcinoma is controversial. We

3 studied the value of known SNPs in genes involved in 5-FU metabolism as biomarkers of chemotherapy

4 response in stage III colon carcinoma patients.

5 Methods: DNA was isolated from normal colonic tissue of 60 stage III colon carcinoma patients treated

6 adjuvantly with 5-FU combined with leucovorin. The tested SNPs were validated SNPs on the OPRT,

7 TYMS and DPYD genes and a synonymous SNP on the TYMP gene. Real time PCR, sequencing and

8 RFLP were used for genotyping..

9 Results: None of the studied genotypes was associated with any of the tumor or patient characteristics.

10 Moreover, none of the genotypes studied had effect on patient survival.

11 Conclusion: In conclusion, the tested SNPs are not biomarkers of chemotherapy response in our stage III

12 colon cancer patients group.

13

14

15

16 Keywords: 5-FU, colon carcinoma, OPRT, DPYD, TYMS, TYMP, SNP

17 


\section{Introduction}

2 In colon cancer, the role of pharmacogenetics for drug toxicity and efficacy is still under discussion [1].

3 5-Fluorouracil (5-FU) is the main drug of choice in the treatment of stage III colon carcinoma. Several

4 proteins are involved in the metabolism of 5-FU and many of the genes coding for these proteins have been

5 shown to be polymorphic.

6 Ororate phosphorybosil transferase (OPRT) and thymidine phosphorylase (TP) activate 5-FU by

7 phosphorylation into active metabolites which respectively incorporate into RNA or inhibit thymidylate

8 synthase (TS). Dihydropyrimidine dehydrogenase (DPD) inactivates 5-FU in the liver [2, 3]. The genes

9 encoding for these proteins harbor functional polymorphisms.

10 The OPRT gene contains several polymorphisms, among those the G638C SNP causes a Gly ${ }^{213} \mathrm{Ala}$

11 substitution. This SNP has been associated with a higher expression and activity of the protein and with an

12 increased toxicity of 5-FU therapy [4].

13 There are several polymorphisms described in the TP gene (TYMP), however there are no confirmed

14 polymorphisms in coding regions causing changes in aminoacid sequence. The value of these

15 polymorphisms as markers of response to 5-FU therapy is to our knowledge, unknown.

16 The polymorphisms in the enhancer region of the TS gene (TYMS) have been widely studied in their

17 relation to response to 5-FU therapy and with protein expression and activity. The studied polymorphisms

18 consist in a $28 \mathrm{bp}$ repeat at the 5 ' untranslated region of the gene and a G>C SNP in the second repeat of the

19 three repeat allele. In the Caucasian population the variants with two (2R) or three (3R) repeats are the most

20 frequent alleles found. On the basis of the effects of the SNP in the second repeat of the 3R allele on TS

21 protein expression, patients could be classified as high TS protein producers when carrying the $\mathrm{G}$ allele and

22 low TS protein producers when carrying the $\mathrm{C}$ allele $[5,6]$. However, up to date, the results concerning the

23 effect of these polymorphisms in 5-FU response remain inconclusive [7].

24 Finally, the DPYD gene has been shown to play a very important role in toxicity of 5-FU. The

25 polymorphism in the exon/intron boundary at exon 14 is responsible for severe toxicity in these patients

26 [8]. However, little is known about the value of these and other polymorphisms as markers of response.

27 We aimed to study the value of known polymorphisms in the OPRT, TYMP, TYMS and DPYD genes as

28 markers of response in stage III colon carcinoma patients treated with 5-FU chemotherapy in combination 
1 with leucovorin.

2

3 


\section{$1 \quad$ Materials and methods}

2 Patient material

3 Sixty stage III colon carcinoma patients treated with surgery and 5-FU chemotherapy following the Mayo

4 regime were studied.

5 All diagnoses were made at a central laboratory for pathology between 2003 and 2004. Population data

6 were obtained from the cancer registry database of the Comprehensive Cancer Centre South. Follow-up

7 information was obtained from medical records.

8 The use of clinical material for this retrospective study was approved by the institutional review board

9 according to the guidelines of the Dutch Federation of Research Associations.

10 DNA was isolated from normal colonic mucosa from formalin fixed paraffin embedded (FFPE) material

11 after proteinase K digestion and purification using the HPTTP kit (Roche, Almere, the Netherlands).

12 Target genes and polymorphisms

13 Polymorphisms must be non synonymous and confirmed by independent research groups. However, in the

14 case of the TYMP gene, there were no confirmed non synonymous polymorphisms and therefore we chose

15 one confirmed synonymous polymorphism.

$16 \quad O P R T$

17 The G638C SNP (rs1801019) causing a Gly213Ala substitution was tested by real time PCR with the

18 following primers and probes forward 5' GCT GAG ACA GTT GGG AGA GTG A 3', reverse 5' TGA

19 GTT CTT TGG GTG CTT CCT T 3', probe for G allele 6FAM 5'CGA ATC ATA ATG GTT C3'and

20 probe for C allele 6FAM 5'AGC GAA TCA TAA TGC TT3'. Reactions were performed using Roche

21 chemistry in a final volume of $20 \mu \mathrm{l}$ in the light cycler v2 (Roche, Almere, the Netherlands).

22 TYMP

23 The rs470119 SNP was assessed by restriction fragment length polymorphism (RFLP). PCR was performed

24 using the following primers forward 6FAM-5'TCC AGA GCC CAG GTA3' and reverse 5'CTG GCC

25 AGG GTC TCC ATC A3'. The 71 bp long PCR product was then digested with MboI restriction enzyme

26 (New England Biolabs, Ipswich, United Kingdom). After digestion, fragment length analysis was carried

27 out by capillary electrophoresis. The following fragment length was expected for homozygous GG, 40bp

28 and 30bp, for AA $71 \mathrm{bp}$ and for heterozygous AG 71bp, 40bp and 30bp. 
2 The two polymorphisms in the enhancer region of this gene were typed using PCR and RFLP as described

3 elsewhere [9]. Briefly, the 28 bp repeat was typed by PCR means followed by electrophoresis on $2 \%$

4 agarose gel. The G>C SNP was typed by digestion of the PCR product with HaeIII restriction enzyme. The

5 G to $\mathrm{C}$ substitution abrogates the restriction site for this enzyme. Subsequently, products were separated by

6 agarose gel electrophoresis.

$7 \quad D Y P D$

8 The SNP A1627G (rs1801159) causing Ile543Val was tested by PCR followed by sequencing using the

9 following primers, forward 5'GCA GTC ACA ATA TGG AGC3' and reverse 5'TTA CCT TAT CAA

10 GAG AGA AAG TT3'. The expected length of the product was 225 bp. Subsequently, PCR products were

11 purified using enzymatic purification with ExoSapIT (USB, USA) and the sequencing reaction was

12 performed using the same primers as for the PCR reaction and Big Dye chemistry (Applied Biosystems,

13 Nieuwerkerk aan den Ijssel, the Netherlands). Sequences were analyzed using the sequencing analysis 5.3.3

14 software (Applied Biosystems)

15 Statistical Analysis

16 SPSS software package for Windows (Chicago, Il., U.S.A.) was used for statistical analysis.

17 Categorical data were analyzed by means of a chi-square or Fischer's exact test. The end point of

18 this study was progression free survival (PFS, time between surgery and disease progression).

19 Univariate survival analysis was performed by Kaplan Meier analysis and differences were analyzed using

20 the Log Rank method. Hazard Ratios and multivariate analysis were calculated using the Cox Proportional

21 Hazard model.

22 All tests are two tailed and a result was considered significant when $\mathrm{p}=0.05$. 


\section{Results}

2 Briefly, characteristics of the sixty patients studied were as follows, median age at diagnosis was 64 years

3 (range 30-81), fifty two percent $(n=31)$ of the tumors were located on the right side of the colon and 53\%

$4(n=32)$ of the patients were male. The majority $70 \%(n=42)$ had a T3 tumor. Median follow up was 39

5 months (range 2-57). $40 \%$ was still alive without evidence of disease at the end of the follow up, $24 \%$ had

6 developed a local recidive or a distant metastasis, $31 \%$ was dead because of cancer related causes and 5.2\%

7 was dead because of non cancer related causes as specified in their medical records. Median time to

8 progression was 15 months (range 6-47)

9 Frequencies of the different alleles are shown in table 1. All frequencies followed Hardy-Weinberg

10 equilibrium and did not differ significantly from frequencies published on the hapmap database for the

11 Caucasian population.

12 In this group of patients, there were no significant associations between any of the genotypes found and any

13 of the clinical and histopathological variables tested including gender, tumor location, $\mathrm{T}$ stage and $\mathrm{N}$ stage.

14 Survival Analysis

15 For the survival analysis, TYMS SNP genotypes were grouped as putative high TS expression (genotypes

$162 \mathrm{R} / 3 \mathrm{G}, 3 \mathrm{C} / 3 \mathrm{G}$ and $3 \mathrm{G} / 3 \mathrm{G})$ and putative low $\mathrm{TS}$ expression $(2 \mathrm{R} / 2 \mathrm{R}, 2 \mathrm{R} / 3 \mathrm{C}$. $3 \mathrm{C} / 3 \mathrm{C})$. No effect on

17 progression free survival of the several genotypes found was seen in a univariate (figure 1) or in a

18 multivariate survival analysis, containing other known prognostic variables for colon carcinoma such as $\mathrm{T}$

19 stage and $\mathrm{N}$ stage of the tumor. 


\section{Discussion}

2 We aimed to study whether known SNPs in genes involved in 5-FU metabolism were good markers of

3 therapy response in stage III colon carcinoma patients.

4 According to our results, we conclude that the SNPs tested in the OPRT, TYMP, TYMS and DPYD genes

5 are not good markers of therapy response in the present cohort. No effect on survival of the different

6 genotypes was seen, however, results should be considered with caution due to the small number of patients

7 analyzed.

8 Although, increased expression of OPRT mRNA and protein activity have been related to a shorter survival

9 of colorectal carcinoma patients treated with 5-FU [10-12] together with the fact that the studied SNP has

10 been proven to be associated to a higher protein expression and activity [13] [4], no effects of the different

11 genotypes in DFS was seen in the present cohort. The OPRT CC variant is very rare in the general

12 population. Our results reflect the low frequency of this genotype in the Caucasian population. If the CC

13 variant would have an effect on survival, the fact that it is such a rare variant makes it very difficult to

14 prove since numbers of patients needed would be very large.

15 The existing literature is more conclusive about TP protein expression which seems to have no influence in

16 survival of colorectal patients [14-19]. Accordingly, the SNP in the TYMP gene was not a good marker for

17 therapy response in our group.

18 The role of the typed polymorphisms on the TYMS gene remains controversial. It has been widely studied

19 as protein and mRNA expression as well as DNA genotyping, still the results are inconclusive as reviewed

20 by Popat et al [7]. These contradictory results are probably due to differences in methodology, technology

21 and patients' selection. In the present patient group, TYMS polymorphisms in the enhancer region are not

22 good markers of therapy response, even when grouping patient by category of putative TS expression no

23 difference in survival was found between putative low and high producers. These results agree with

24 previous results in a larger cohort of patients [20].

25 Finally, although DPYD has been widely studied in relation to 5-FU toxicity, it also seems to have a role in

26 outcome [15, 19, 21-23]. However, whether this effect is due to the enzyme itself or due to high toxicity

27 and subsequent therapy interruption is not clear. In the present cohort of patients, the studied SNP is not a

28 good marker of therapy response.

29 In conclusion, polymorphisms in genes involved in 5-FU metabolism are not valuable as markers of

30 response in the present cohort of colon cancer patients. Recently, the results of a clinical trial over the value 
1 of some polymorphisms in predicting toxicity in a large group of colon carcinoma patients failed to find

2 any relation between the tested SNPs and toxicity [1]. In that study the value of several SNPs involved in 5-

3 FU metabolism was tested in relation to toxicity. In the same way, we cannot show any value of these SNPs

4 as markers of response to 5-FU in our group of patients. 
2

1. Braun, M.S., et al., Association of Molecular Markers With Toxicity Outcomes in a Randomized Trial of Chemotherapy for Advanced Colorectal Cancer: The FOCUS Trial. J Clin Oncol, 2009.

2. Longley, D.B., W.L. Allen, and P.G. Johnston, Drug resistance, predictive markers and pharmacogenomics in colorectal cancer. Biochim Biophys Acta, 2006. 1766(2): p. 184-96.

3. Longley, D.B., D.P. Harkin, and P.G. Johnston, 5-fluorouracil: mechanisms of action and clinical strategies. Nat Rev Cancer, 2003. 3(5): p. 330-8.

4. Ichikawa, W., et al., Orotate phosphoribosyltransferase gene polymorphism predicts toxicity in patients treated with bolus 5-fluorouracil regimen. Clin Cancer Res, 2006. 12(13): p. 3928-34.

5. Kawakami, K. and Y. Watanabe, Identification and functional analysis of single nucleotide polymorphism in the tandem repeat sequence of thymidylate synthase gene. Cancer Res, 2003. 63: p. 6004-6007.

6. Mandola, M.V., et al., A novel single nucleotide polymorphism within $5^{\prime}$ tandem repeat polymorphism of the thymidylate synthase gene abolishes USF-1 binding and alters transcriptional activity. Cancer Res, 2003. 63: p. 3898-2904.

7. Popat, S., A. Matakidoue, and R.S. Houlston, Thymidylate synthase expression and prognosis in colorectal cancer: a systematic review and meta-analysis. J Clin Oncol, 2004. 22(3): p. 529-536.

8. Vallböhmer, D., et al., DPD is a molecular determinant of capecitabine efficacy in colorectal cancer. Int J Oncol, 2007. 31(2): p. 413-8.

9. Gosens, M.J., et al., Thymidylate synthase genotyping is more predictive for therapy response than immunohistochemistry in patients with colon cancer. Int $\mathbf{J}$ Cancer, 2008. 123(8): p. 1941-9.

10. Ishikawa, M., T. Miyauchi, and Y. Kashiwagi, Clinical implications of thymidylate synthetase, dihydropyrimidine dehydrogenase and orotate phosphoribosyl transferase activity levels in colorectal carcinoma following radical resection and administration of adjuvant 5-FU chemotherapy. BMC Cancer, 2008. 8: p. 188.

11. Ochiai, T., et al., Prognostic impact of orotate phosphoribosyl transferase among 5-fluorouracil metabolic enzymes in resectable colorectal cancers treated by oral 5-fluorouracil-based adjuvant chemotherapy. Int J Cancer, 2006. 118(12): p. 3084-8.

12. Ochiai, T., et al., Prognostic impact of ororate phosphoribosyl transferase activity in resectable colorectal cancers treated by 5-fluorouracil-based adjuvant chemotherapy. J Surg Oncol, 2006. 94: p. 45-50.

13. Suchi, M., et al., Molecular cloning of the human UMP synthase gene and characterization of point mutations in two hereditary orotic aciduria families. Am J Hum Genet, 1997. 60(3): p. 525-39.

14. Artinyan, A., et al., Molecular predictors of lymph node metastasis in colon cancer: increased risk with decreased thymidylate synthase expression. J Gastroint Surg, 2005. 9: p. 1216-1221. 
15. Ciaparrone, M., et al., Predictive role of thymidylate synthase, dihydropyrimidine dehydrogenase and thymidine phosphorylase expression in colorectal cancer patients receiving adjuvant 5-fluorouracil. Oncology, 2006. 70: p. 366-377.

16. Lassmann, S., et al., Predictive molecular markers for colorectal cancer patients with resected liver metastasis and adjuvant chemotherapy. Gastroenterology, 2007. 133: p. 1831-1839.

17. Liersch, T., et al., Lymph node status and TS gene expression are prognostic markers in stage II/III rectal cancer after neoadjuvant fluorouracil-based chemoradiotherapy. J Clin Oncol, 2006. 24(25): p. 4062-4068.

18. Metzger, R., et al., High basal level gene expression of thymidine phosphorylase (platelet-derived endothelial cell growth factor) in colorectal tumors is associated with nonresponse to 5-fluorouracil. Clin Cancer Res, 1998. 4: p. 2371-2376.

19. Yanagisawa, Y., et al., Modified irinotecan/5-FU/Leucovorin therapy in advanced colorectal cancer and predicting therapeutic efficacy by expression of tumorrelated enzymes. Scan J Gastroenterol, 2007. 42: p. 477-484.

20. Farina-Sarasqueta, A., et al., TS gene polymorphisms are not good markers of response to 5-FU therapy in stage III colon cancer patients. Cell Oncol, 2010.

21. Tokunaga, Y., H. Sasaki, and T. Saito, Clinical role of ororate phosphoribosyltransferase and dihydropyrimidine dehydrogenase in colorectal cancer treated with postoperative fluoropyrimidine. Surgery, 2007. 141: p. 346353.

22. Tsuji, T., et al., Tumor dihydropyrimidine dehydrogenase expression is a useful marker in adjuvant therapy with oral fluoropyrimidines after curative resection of colorectal cancer. Cancer Chemother Pharmacol, 2004. 54: p. 531-536.

23. Westra, J.L., et al., Predictive value of thymidylate synthase and dihydropyrimidine dehydrogenase protein expression on survival in adjuvantly treated stage III colon cancer patients. Ann Oncol, 2005. 16: p. 1646-1653. 
1 Tables and figures

2 Table 1: Frequencies of the different alleles

\begin{tabular}{|c|c|}
\hline SNIPS & rrequencles N(\%) \\
\hline OPRT & \\
GG & $44(75)$ \\
GC & $15(25)$ \\
CC & $0(0)$ \\
\hline TYMP & \\
GG & $25(42)$ \\
AG & $29(48)$ \\
AA & $6(10)$ \\
\hline TYMS & \\
2 repeats & $10(17)$ \\
2 \& repeats & $35(58)$ \\
3 repeats & $15(25)$ \\
\hline TYMS SNP & \\
2R/2R & $10(16.7)$ \\
2R/3RC & $16(26.7)$ \\
2R/3RG & $19(31.7)$ \\
3RC/3RC & $7(11.7)$ \\
3RG/3RC & $4(6.7)$ \\
3RG/3RG & $4(6.7)$ \\
\hline DPYD & \\
AA & $37(67)$ \\
AG & $14(26)$ \\
GG & $4(7)$ \\
\hline
\end{tabular}

3

4

5

6

7

8

9

10

Figure 1: Kaplan Meier Curves for PFS according to all genotypes tested; a) TYMP genotypes, b) OPRT, c) DPYD, d)TYMS

repeat e) TYMS expression category determined by SNP genotypes (Low expression 2R/2R, 2R/3C, 3C/3C; High expression 2R/3G and $3 G / 3 G)$ 